\title{
COMPARATIVE ANALYSIS OF HEALTH AND ECONOMIC GROWTH NEXUS: A CASE STUDY OF BANGLADESH, INDIA AND PAKISTAN
}

\author{
Muska Nazir \\ BS Economics Student, Department of Economics, \\ University of Peshawar \\ Muska.20@pide.edu.pk \\ Dr. Ahmed Farhan Saeed \\ Assistant Professor \\ Area Study Centre (Russia, China \& Central Asia) \\ University of Peshawar \\ drfarhan@uop.edu.pk \\ Dr. Sanam Wagma Khattak \\ Ph.D. Lecturer at Department of Economics, \\ University of Peshawar \\ sanamah@uop.edu.pk
}

\begin{abstract}
Health is one of the key factor that determines the growth of an economy. It is the improved health of the labor that can translate into increased output levels, higher level of productivity and efficient utilization of resources. For the study, Pooled OLS regression over the period from 1980-2017 is applied on panel data to find the results of health and economic growth nexus for three lower middle income countries that are Bangladesh, India and Pakistan. For Pakistan, Bangladesh and India, their statistics provides further support to existing literature showing a significant and positive relationship of health with economic growth. Comparing their results, it is found that India's better health facilities are contributing more towards economic growth as compared to Pakistan and Bangladesh. Therefore, their focus too should be on improvement of health indicators in order to achieve higher economic growth levels.
\end{abstract}

Keywords: comparative analysis, health, economic growth, life expectancy, crude birth rate 


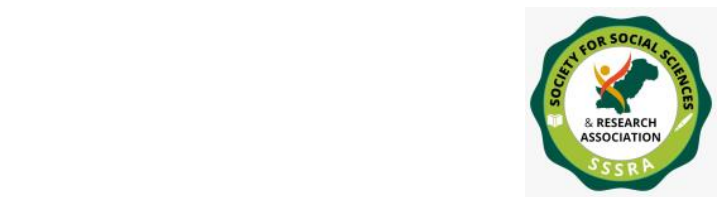

Pak. Journal of Int'L Affairs, Vol 4, Issue 1 (2021)

Comparative Analysis of Health and ...

\section{Introduction}

Efficient use of resources leads to growth in an economy. Economic growth indicates the progress and development in the country. With the developments in study of growth equation, economic factors are not the only determinants of growth, but the noneconomic factors are also considered, providing a new perspective to the study of growth (Hakim, \& Subanti, 2019 October). Therefore, there are many factors that determine the growth of a country. One the most important factor among them is the health of labor as it provides help by increasing their output level, boosting their productivity and most of all enabling them in enhancing the competence of accessible resources.

It is a healthy human being who can perform all the possible physical and intellectual activities for better living standards. Better health being an ultimate gift to mankind can be used as an asset for the progress of economic growth in a country. But when health is not taken care of it can also become an obstacle in economic growth. As an unhealthy individual will have lower or no efficiency in performance leading to lesser productivity levels (Bokhari, Gardezi, 2013). Lower output levels is in turn a straight route to a decreased growth in the economy.

\section{Health Scenario in Pakistan}

Pakistan has mixed health system with public, private, civil society and donor contributors (Kumar, 2017). Pakistan ranks $152^{\text {nd }}$ among 189 countries on the human development index and falls in the medium human development category. While it's MPI estimation shows 38.3 percent of population to be multidimensionally poor (Conceição, 2019). Since 2000, there has been improvements in some of the health indicators because of contributions made by NGO's, public and private sectors (Kumar, 2017). Still Pakistan health situation is in dire states with increasing infant mortality rates and population growth rates. (Akram, Ihtsham ul Haq Padda, \& Khan, 2008) This may be the outcome of low health expenditure in Pakistan over the last years (Akram, Ihtsham ul Haq Padda, \& Khan, 2008). Regardless, the country is going through considerable reforms in its health system bringing improvements in health indicators. Health expenditure in Pakistan increased to 2.75 percent of GDP during the fiscal year 2016-17 from 2.75 of last year but was still low compared to other developing countries (World Bank, 2019). The conveyance of health care facilities in Pakistan is also inefficient in rural areas while priority is given to urban areas (Akram, Ihtsham ul Haq Padda, \& Khan, 2008). The graph depicts a positive relation between life expectancy and economic growth which is consistent with the theory. The vertical axis show life expectancy while horizontal axis show GDP at current prices. 


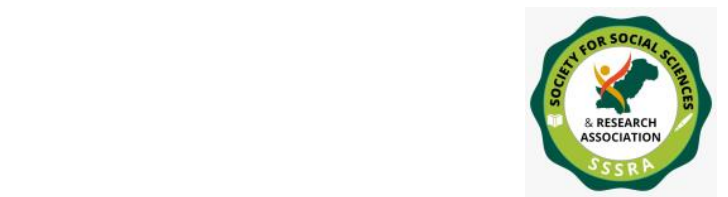

Figure 1 Relation of life expectancy and Economic growth

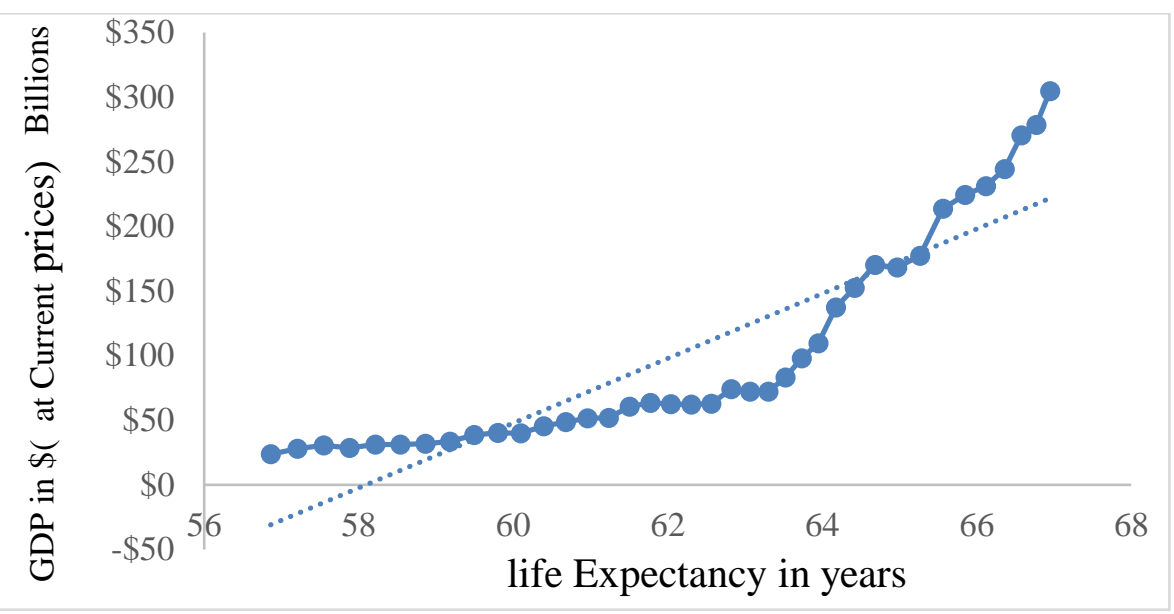

\section{Health scenario in Bangladesh}

Bangladesh ranks 135th out of 189 countries on the human development index while its MPI estimation shows 16.7 percent of the population to be in severe multidimensional poverty (Conceição, 2019). The current health expenditure of Bangladesh was 2.36 percent of GDP for year 2016 as compared to 2.46 in the last year (World Bank, 2019). Bangladesh government has implemented various programs for the development of its health sector. This has led to progress in the health indicators like increased life expectancy and decreased mortality rates. Also the priority given to health, nutrition and population by the government the health sector has shown improving results in Bangladesh (Jasimuddin \& Chowdary, 2018). In Bangladesh, HPNSDP (Health, Population and Nutrition Sector Development Program) an integrated sector program has been established for the achievement of health goals sustainably.

\section{Health Scenario in India}

According to (Conceição, 2019). report India ranks $129^{\text {th }}$ on the human development index which is higher than last year ranking while the MPI estimation shows 8.8 percent population to be in severe multidimensional poverty. Over the last years health indicators in India have improved. Other than public sector, private sector and other NGOs also provide health care facilities. However, having a large number of population makes it challenging to carter the needs of all citizens even though hospitals, public health centers and other medical facilities are available (Jawahar, 2013). According to Article 39, 41, 


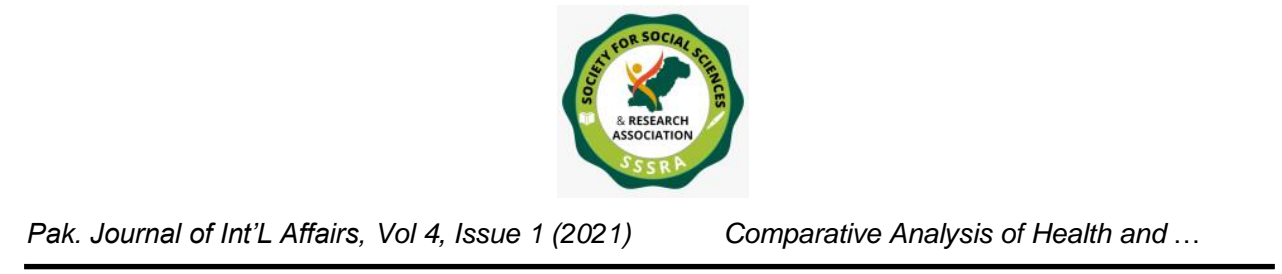

42 and 47 in the directive principle of state policy, ensuring basic nutrition, living standards and improving public health are the responsibilities of the state.

The purpose of present study is to examine the impact of health on economic growth for Pakistan, India and Bangladesh with the intention of comparing their results in order to examine the pattern and trend in the health and economic growth nexus of the chosen countries. Analyzing the growth in comparative study framework provides a careful examination of the institutions in a particular country. Being lower-middle income countries and situated in the same region, the comparative analysis of Pakistan, India and Bangladesh for health-growth nexus thus have important policy implications for health sector in a sense the emphasis each country has put on the development of its health indicators which has in turn led to economic growth.

\section{Hypothesis of the Study}

The present study have the following sets of hypothesis;

Ho: Health does not have impact on economic growth of Pakistan, India and Bangladesh. Ha: Health does have impact on economic growth of Pakistan, India and Bangladesh.

\section{Literature Review}

A considerable amount of literature is present on studies signifying the relation of health indicators on economic growth. Though no such research has been conducted on comparative analyzation of the health impact on economic growth between Pakistan, India and Bangladesh. This chapter therefore reviews the previous literature nexus between economic growth and health of the country.

In order to investigate the relationship of growth taken as GDP and health indicators, (Kesikoğlu \& Öztürk, 2013) conducted a study and found there to be a positive relation between the two factors such as rise in one causes increase in the other factor. In other words, they considered GDP to be an important factor of health spending. The sample taken for the study was OECD countries. The study also concluded OECD countries panel to be an unidentical group.

According to (Fogel, 1994), from 1790 to 1980 about one third of the GDP of Britain was due to the improvement in health facilities specially in nutrition, public health and medical care and should be considered as labor enhancing.

In 2001, Mayer in his study said that "improvement in health facilities enhances productivity and income growth." The data was taken from 1950-1990 for Latin America 


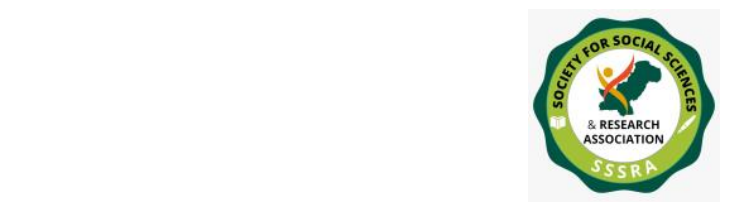

Pak. Journal of Int'L Affairs, Vol 4, Issue 1 (2021)

Comparative Analysis of Health and ...

while he applied GLS technique. The variables used were fertility rate, government consumption, prime education and life expectancy (Mayer, 2001). In the same year adult survival rate were said to be an increasing factor of economic growth in low income countries (Boachie, 2015).

According to (Arora, 2001) public expenditure on health improves food productivity and information about diseases. He took the data of 10 industrial economies for one century to describe the relation among health and growth. The study showed that in industrial states the economic growth rises up to $40 \%$ with the improvement in labor's health while the increased rate of mortality causes the growth levels to decrease in developing countries. Health is indeed an indispensable factor of growth. It is a healthy individual who is able to perform the daily activities without being a burden on the society. Health being the main element of human capital lifts the worker's capability and improves output.

According to (Bloom, Canning, \& Sevilla, 2004) the basic trigger of economic growth is education and health of the individuals. Health is considered a key social indicator for development. Thus, it is taken as basic element of growth (Bokhari, \& Gardezi, 2013). For the third world countries the main concern for policy makers is education and health. Same is the case for Pakistan as the mostly used method of production is mainly labor intensive.

The association between healthcare expenditure (HCE) and economic growth (GDP) was also investigated by (Carrion-i-Silvestre, 2005). For the study he took the data of OECD countries to find the relationship. Results of the study showed an encouraging effect of healthcare expenditure on economic growth of the countries. It further explained that countries spending relatively more on the healthcare experiences higher productivity rates in the long-run compared to the countries that have allocated smaller proportion of their budget to the healthcare of their country.

Economic growth and improved health have a two way relationship i.e. improved health causes an increase in per capita GDP by rising output levels along with resource accumulation and technological change. This leads to an increase in income which is then spent again on investments in human capital which further results in per capita growth (Akram, Ihtsham ul Haq Padda, \& Khan, 2008).

Health plays a vital role in the sustainable economic growth making it a significant factor in the process of growth. In economic literature human capital is defined by the inclusion of health, education, migration, training and all other investments that increase the 


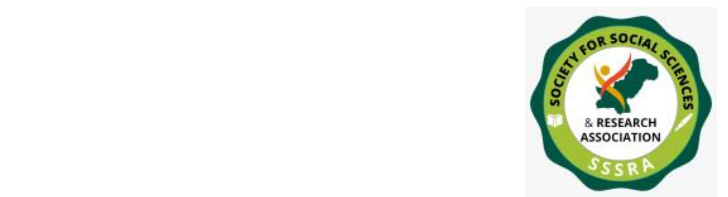

Comparative Analysis of Health and ...

productivity levels of an individual. However, the growth economists have only incorporated in their analyzation, the impact of education on economic growth while paying trivial attention to health in the human capital. Thus, only in the recent times have the relationship between health and economic growth been estimated (Akram, Ihtsham ul Haq Padda, \& Khan, 2008).

Observing the integration among well-being and financial growth for five states for period of 1974-2007 Narayan results supported the previous literature by showing that health is an important element of growth. He concluded that with better health comes higher productivity rates leading to economic growth in the country. Therefore, in order to increase the growth rates of economy, a state needs to focus on the health indicators (Narayan, Narayan, \& Mishra, 2010).

In 2011, Swift empirically investigated the association between life expectancy and GDP to confirm their co-integration. The study took the data for 13 OECD countries for time period of two hundred years. Application of co-integration techniques on the data showed that life expectancy rate and GDP are related at ratio of 1:6. Such as, one percent enhancement in life expectancy rate causes a six percent growth in economic growth of the country. These results were significantly important in a sense that only a minute improvement in life expectancy of individuals in given country can bring out a larger positive change in the growth of the economy (Swift, 2011).

A bidirectional association among healthcare facilities HCE and growth GDP were conducted for period of 1970-2009. Data for 20 OECD countries was taken to investigate the given relationship. Results showed there to be a positive association between healthcare facilities and growth providing further support to the existing literature (Amiri, $\&$ Ventelou, 2012). Same results were found for China for the time period of 1978 to 2003 proving the existence of positive relation between health improvement and growth (Gong, Li, \& Wang, 2012).

Similarly, conducting the study for 31 OECD countries showed that healthcare facilities have encouraging effect on growth. The study also made comparison of public and private share in the health expenditure relation to growth. Results showed that private share in health expenditure has more significant relation to growth as compared to public share in health expenditures (Lago-Penas, 2013).

Examining the effect of life expectancy to real income of individuals of Bangladesh a study concluded that life expectation rises the real income of Bangladeshi people. It also showed that comparing the male and females life expectancy ratios, the life expectancy 


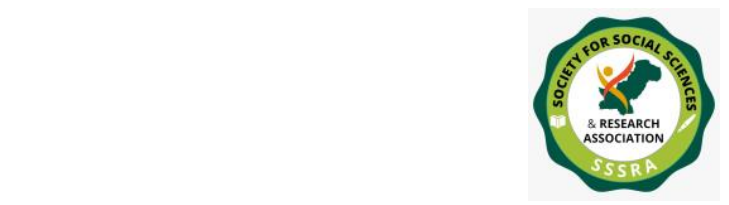

Comparative Analysis of Health and ...

rates were greater in females than males in the previous one and half decades (Mahumud, Rawal, Hossain, \& Islam, 2013). Investigating the relation of health indicators and household income of people of China, Goode \& Mavromaras analysis of results showed that household income has a strong influence on Chinese children health (Goode, \& Mavromaras, 2014). Healthcare expenditures has an encouraging effect on the growth rates. For studying this relationship between HCE and GDP, data for 28 European member countries over period of 1974-2015 was chosen. The application of adaptive neuro-fuzzy technique provided empirical statistics to the equation (Mladenovic et al, 2016).

In case of Greece, Katrakils found a one-sided causality of income to newborn mortality for time period of 1960-2012. Analysis showed that economic growth has progressive effect on the quality of health (Katrakilidis, 2016). Similarly, health-growth causal correlation over period of 1995-2013 for a panel of 51 states and found the same results (Chaabouni, Zghidi, \& Mbarek, 2016). The relationship for CEMAC (the Central African Economic and Monetary Community) states was also the same (Piabuo, \& Tieguhong, 2017). However a study revealed that GDP per capita is adversely correlated with mortality rate in in case of 38 Chinese provinces for period of 2002-2014 (Ning, \& Zhang, 2018).

In another study on a sample of 148 countries for period of 1970-2010, Linden and Ray discovered that a basic reason of life expectations was GDP per capita (Linden, \& Ray 2017). For Africa, (Zaidi, \& Saidi, 2018), discovered the same results for health expenditures and GDP per capita over the period of 1990 to 2015.

Siddique considers education and health as indispensable factors of economic growth. Studying the data of 76 middle income countries from 1991-2016, they have used fixed and random effect approaches for investigating the impact of health and education on economic growth. The empirical findings reveals positive link between life expectancy and economic growth while inverse relation exists between economic growth and infant mortality. While the secondary and tertiary level education contributes to increase in financial development. The results also showed negative impact of labor and positive influence of capital on economic growth. Comparison of upper middle income countries (UMIC) with the lower middle income countries (LMIC) shows that impact of life expectancy, enrollment in secondary and tertiary education, infant mortality, on economic growth is stronger in upper middle income countries than in lower middle income countries. Therefore, the focus of economies, particularly the lower income states should be towards improving the health and education facilities in order to surge economic growth of the country (Siddique, Mohey-ud-din, \& Kiani, 2018). 


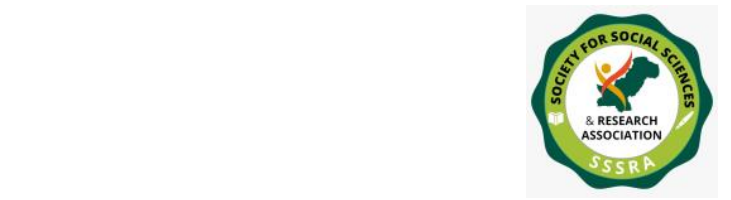

Comparative Analysis of Health and ...

The study of previous literature leaves no doubt about health being an essential factor of growth which can be used for enhancing the productivity levels within an economy and in turn increasing the GDP of a country. Preceding literature on cross-countries analysis also shows that little attention has been given to empirical analysis of developing nations. Therefore, the present study focuses on alternative empirical strategy to investigate the importance of crude birth rate and life expectancy on economic growth for three lowermiddle income countries that are Pakistan, India and Bangladesh.

\section{Materials and methods}

For the purpose of the study panel data analysis is used as it controls the effects of missing and unobservable variables as well as the individual heterogeneity. Multicollinearity is also reduced when panel data analysis is used. Also in panel data analysis there is high sample variability and degree of freedom which causes the competency of parameter estimates to be high. Numerous models have been developed to incorporate the effect of health in economic growth. One of the most important factor in determining economic growth is health of individuals (Barro, 1996). Since the focus of the study is to analyze the effects of health on economic growth, we take the growth model of (Romer, 1990) and derive our model from it. Such as

$\mathrm{Y}=\mathrm{f}(\mathrm{H})$

Where $\mathrm{Y}$ is the output while $\mathrm{H}$ represents the health of individuals.

For health two proxies are used in the study that are life expectancy rate and crude birth rate. So equation (i) becomes;

$\mathrm{Y}=\mathrm{f}(\mathrm{LE}, \mathrm{CBRT})$

GDP at constant prices is taken to measure the economic growth of the countries. Substituting it in equation (ii) it becomes;

$\mathrm{GDP}=\mathrm{f}(\mathrm{LE}, \mathrm{CBRT})$

$\mathrm{GDP}=\alpha_{0}+\alpha_{1} \mathrm{LE}+\alpha_{2} \mathrm{CBRT}+\mathrm{e}$ (iv)

Since our analysis is based on paned data, equation (iv) becomes;

GDPit $=\alpha_{0}+\alpha_{1}$ LEit $+\alpha_{2}$ CBRTit + eit $\ldots \ldots \ldots \ldots . .(\mathrm{v})$ 


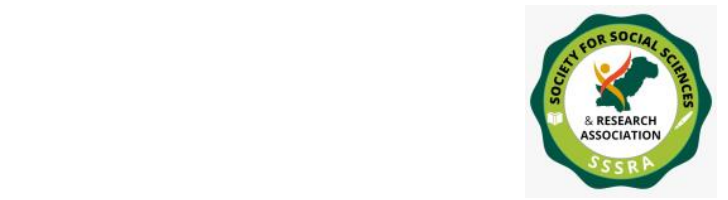

Pak. Journal of Int'L Affairs, Vol 4, Issue 1 (2021)

Comparative Analysis of Health and ...

Taking log of the above equation and in explicit terms equation (v) can be written as;

LOG(GDP)

$=\mathrm{C}(1)+\mathrm{C}(2) * \mathrm{LOG}(\mathrm{CBR})+\mathrm{C}(3) * \mathrm{LOG}(\mathrm{LE})+\mathrm{C}(4) * \mathrm{Dummy}+\mathrm{C}(5) * \mathrm{D} 2+\mathrm{C}(6) * \mathrm{D} 3$

where, GDP = gross domestic product at constant prices of a country

$\mathrm{LE}=$ life expectancy rate in years of a country

$\mathrm{CBRT}=$ crude birth rate per 1000 population estimated at midyear of a country

$\mathrm{C}(1)=$ constant term

$\mathrm{C}(2)$ and $\mathrm{C}(3)=$ parameter estimates of crude birth rate and life expectancy rate respectively

$\mathrm{C}(4), \mathrm{C}(5)$ and $\mathrm{C}(6)$ are coefficients of dummy variables

"Dummy" is used for Bangladesh, "D2" for India and "D3" for Pakistan

term ' $i$ ' indicates cross-sectional units that are Pakistan, India and Bangladesh

term ' $\mathrm{t}$ ' is used for time period 1980-2017

while $\mathrm{e}=$ error term .

\section{Results and Discussion}

Results show that crude birth rate has negative and significant overall impact on GDP. When a country has increased birth rate this indicates that the population is increasing. From one side larger number of population would lead to increasing growth in the economy but if we look from the other side we can see that increased number of people in an economy does not always translate into increased productivity in an economy. This is because as the population increases, it might not be the productive labor force that has increased. But the unproductive individuals such as children or retired seniors not actively working and taking part in the economy. Thus provision for them and their noncontributing behaviour in the economy can translate into the given negative impact as shown here in the statistics. Since the relationship is significant, this is to be kept in mind that crude birth rate can be considered a factor effecting growth albeit negatively. 


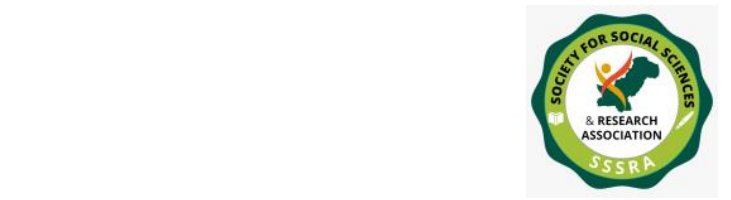

Comparative Analysis of Health and ...

Life expectancy has a significant positive impact on the overall economic growth. Such as one percent increase in life expectancy ratio is accompanied by $5.6 \%$ increased production in the economy. That is if the individuals life expectancy increases, this could mean that the health of population is improving. This improvement in the health of labor force could translate into more output levels being produced or might as well in increased labor efficiency. Thus causing the GDP of an economy to increase as well.

In case of Bangladesh, the relationship between health indicators and economic growth is significant and positive. The positive impact indicates that improved health of individuals leads to greater productivity in an economy and also because the changes in the system has translated into growth for the period taken in the study. For Bangladesh, one percent improvement in health causes $1.73 \%$ increase in the country's output levels.

Same is the case for Pakistan and India, their statistics provides further support to existing literature showing a significant and positive relationship of health with economic growth. Though other factors play role in stimulating economic growth, health too is taken as an important factor of growth. That is one percent increase in health indicators causes $1.86 \%$ and $1.54 \%$ increase in economic growth of India and Pakistan respectively. This also shows that the impact of health on economic growth is more in India than in Pakistan and Bangladesh.

\section{Table 1 Pooled OLS Regression analysis}

Dependent Variable: LOG(GDP)

Date: $03 / 03 / 20$ Time: $14: 52$

Sample: 19802017

Periods included: 38

Cross-sections included: 3

Total panel (balanced) observations: 114

$\mathrm{LOG}(\mathrm{GDP})=\mathrm{C}(1)+\mathrm{C}(2)^{\star} \mathrm{LOG}(\mathrm{CBR})+\mathrm{C}(3)^{\star} \mathrm{LOG}(\mathrm{LE})+\mathrm{C}(4)^{\star} \mathrm{Dummy}+\mathrm{C}(5)^{\star} \mathrm{D} 2+\mathrm{C}(6)^{\star} \mathrm{D} 3$ 


\begin{tabular}{rrrrr}
\hline \hline & Coefficient & Std. Error & t-Statistic & Prob. \\
\hline \hline$\underline{\underline{\mathrm{C}}(1)}$ & 66.38458 & 8.651229 & 7.673428 & 0.0000 \\
$\underline{\underline{\mathrm{C}}(2)}$ & -5.508901 & 0.585764 & 9.404635 & 0.0000 \\
$\underline{\underline{\mathrm{C}(3)}}$ & 5.616841 & 1.619927 & 3.967343 & 0.0008 \\
$\underline{\underline{\mathrm{C}}(4)}$ & 1.730683 & 0.046390 & 37.30736 & 0.0000 \\
$\underline{\underline{\mathrm{C}}(5)}$ & 1.868907 & 0.095199 & 19.63159 & 0.0000 \\
$\underline{\underline{\mathrm{C}}(6)}$ & 1.546190 & 0.120375 & 12.84477 & 0.0000 \\
\hline \hline & & & & \\
R-squared & 0.970477 & Mean dependent var & 25.59857 \\
Adjusted R-squared & 0.969393 & S.D. dependent var & 1.308376 \\
S.E. of regression & 0.228898 & Akaike info criterion & -0.068211 \\
Sum squared resid & 5.710982 & Schwarz criterion & 0.051798 \\
Log likelihood & 8.888037 & Hannan-Quinn criter. & -0.019506 \\
F-statistic & 895.7443 & Durbin-Watson stat & 0.111078 \\
Prob(F-statistic) & 0.000000 & & \\
\hline \hline
\end{tabular}

Significance level $=5 \%$

In the table above, the value of $\mathrm{R}^{2}$ show that $97 \%$ of our dependent variable is explained i.e. GDP is explained by $R^{2}$ and the rest goes to residuals. This high value of $R^{2}(97 \%)$ also indicates that our chosen model is a good fit. This statement is further supported by F.statistc probability which is significant.

The table provides the overall summary of descriptive statistics of variables used in the study. The maximum, minimum, standard deviation and mean values of data along with Jarque-Bara probability for Bangladesh, India and Pakistan are shown. The average value of economic growth is 3.25 while that of crude birth rate and life expectancy are 30.80 and 62.45 respectively. In the following sections descriptive statistics for individual samples are discussed 
Table 2 Descriptive statistics of variables

Descriptive statistics

Sample: 19802017

\begin{tabular}{lcccccc}
\hline \hline & CBR & D2 & D3 & DUMMY & GDP & LE \\
\hline \hline Mean & 30.80247 & 0.333333 & 0.333333 & 0.333333 & $3.25 \mathrm{E}+11$ & 62.45136 \\
Median & 30.48950 & 0.000000 & 0.000000 & 0.000000 & $1.22 \mathrm{E}+11$ & 62.68100 \\
Maximum & 43.03900 & 1.000000 & 1.000000 & 1.000000 & $2.65 \mathrm{E}+12$ & 72.05200 \\
Minimum & 18.08300 & 0.000000 & 0.000000 & 0.000000 & $1.76 \mathrm{E}+10$ & 52.90000 \\
Std. Dev. & 7.305697 & 0.473486 & 0.473486 & 0.473486 & $5.36 \mathrm{E}+11$ & 4.869505 \\
Skewness & -0.008098 & 0.707107 & 0.707107 & 0.707107 & 2.614206 & -0.026027 \\
Kurtosis & 1.961219 & 1.500000 & 1.500000 & 1.500000 & 9.175425 & 2.106667 \\
& & & & & & \\
Jarque-Bara & 5.126811 & 20.18750 & 20.18750 & 20.18750 & 310.9928 & 3.803582 \\
Probability & 0.077042 & 0.000041 & 0.000041 & 0.000041 & 0.000000 & 0.149301 \\
& & & & & & \\
Sum & 3511.482 & 38.00000 & 38.00000 & 38.00000 & $3.71 \mathrm{E}+13$ & 7119.455 \\
Sum Sq. Dev. & 6031.172 & 25.33333 & 25.33333 & 25.33333 & $3.24 \mathrm{E}+25$ & 2679.464 \\
& & & & & & \\
Observations & 114 & 114 & 114 & 114 & 114 & 114
\end{tabular}

Table 3 Descriptive statistics for Bangladesh

\begin{tabular}{|l|c|c|c|}
\hline Variables & CBR & GDP & LE \\
\hline Obs & 38 & 38 & 38 \\
\hline Mean & 29.35255 & $7.06 \mathrm{E}+10$ & 63.42461 \\
\hline Median & 28.48950 & $5.06 \mathrm{E}+10$ & 64.56550 \\
\hline Max & 43.03900 & $2.50 \mathrm{E}+11$ & 72.05200 \\
\hline Min & 18.50100 & $1.76 \mathrm{E}+10$ & 56.86000 \\
\hline Stdd Dex & 7.836425 & $6.00 \mathrm{E}+10$ & 6.261364 \\
\hline Skewness & 0.264868 & 1.484205 & -0.242158 \\
\hline Kurtosis & 1.771730 & 4.372127 & 1.654452 \\
\hline
\end{tabular}


Table 4 Descriptive statistics for India

\begin{tabular}{|l|c|c|c|}
\hline Variables & CBR & GDP & LE \\
\hline Obs & 38 & 38 & 38 \\
\hline Mean & 27.16824 & $8.02 \mathrm{E}+11$ & 61.68671 \\
\hline Median & 27.09250 & $4.40 \mathrm{E}+11$ & 61.88100 \\
\hline Max & 36.16700 & $2.65 \mathrm{E}+12$ & 69.16500 \\
\hline Min & 18.08300 & $1.86 \mathrm{E}+11$ & 53.81400 \\
\hline StdDex & 5.711175 & $7.18 \mathrm{E}+11$ & 4.759006 \\
\hline Skewness & -0.002487 & 1.118565 & -0.040807 \\
\hline Kurtosis & 1.784710 & 2.874285 & 1.740470 \\
\hline
\end{tabular}

Table 5 Descriptive statistics for Pakistan

\begin{tabular}{|l|c|c|c|}
\hline Variables & CBR & GDP & LE \\
\hline Obs & 38 & 38 & 38 \\
\hline Mean & 35.88663 & $1.04 \mathrm{E}+11$ & 62.24276 \\
\hline Median & 35.79600 & $6.31 \mathrm{E}+10$ & 62.43350 \\
\hline Max & 42.26000 & $3.05 \mathrm{E}+11$ & 66.94700 \\
\hline Min & 28.59900 & $2.37 \mathrm{E}+10$ & 52.90000 \\
\hline Std.Dex & 5.167840 & $8.36 \mathrm{E}+10$ & 2.991181 \\
\hline Skewness & -0.015177 & 1.024693 & -0.133844 \\
\hline Kurtosis & 1.371176 & 2.698165 & 1.883377 \\
\hline
\end{tabular}

The maximum value of economic growth i.e. 3.05 belongs to Pakistan and minimum value 1.76 belongs to Bangladesh. The maximum value of life expectancy 72.05 belongs to Bangladesh and minimum value 52.90 is for Pakistan. The maximum value of crude birth rate i.e. 43.03 belongs to Bangladesh and minimum value 18.08 is for India. 
Table 6 Histogram Normality Test

Null hypothesis: residuals are normally distributed

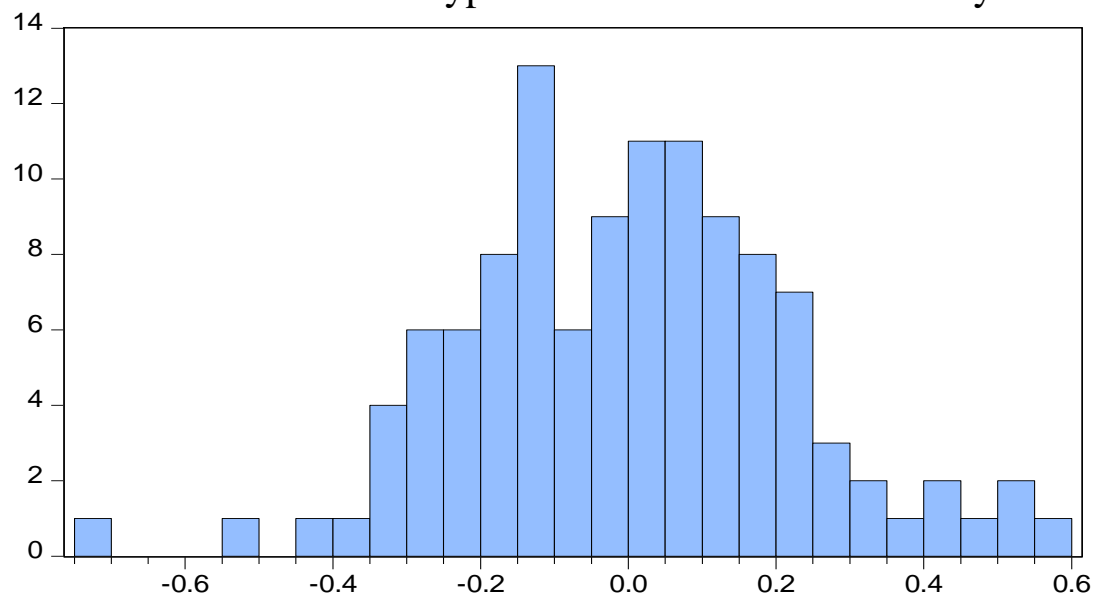

Series: Standardized Residuals Sample 19802017

Observations 114

Mean $\quad-5.76 e-15$

Median $\quad 0.002554$

Maximum 0.597422

Minimum $\quad-0.722654$

Std. Dev. $\quad 0.224810$

Skewness $\quad 0.030552$

Kurtosis $\quad 3.525697$

Jarque-Bera $\quad 1.330434$

Probability 0.514162

Significance level $=5 \%$

To check whether the data is normally distributed, null hypothesis is made that is "residuals are normally distributed". Since the probability of Jarque-Bera is greater than 5 percent, we accept our null hypothesis. This indicates normal distribution of the data or in other words it has a zero mean. As zero mean is an assumption of the ordinary least square, it can be said that we can that an assumption of the OLS is satisfied. The satisfied assumption of OLS gives a significant outlook to derived results.

Table 7 Residual Cross Section Dependence Test

Residual Cross-Section Dependence Test

Null hypothesis: No cross-section dependence (correlation) in residuals

Periods included: 38

Cross-sections included: 3

Total panel observations: 114

\begin{tabular}{lcccc}
\hline \hline & & & & \\
& Test & Statistic & d.f. & Prob. \\
\hline \hline Pesaran CD & & & & \\
\hline \hline
\end{tabular}




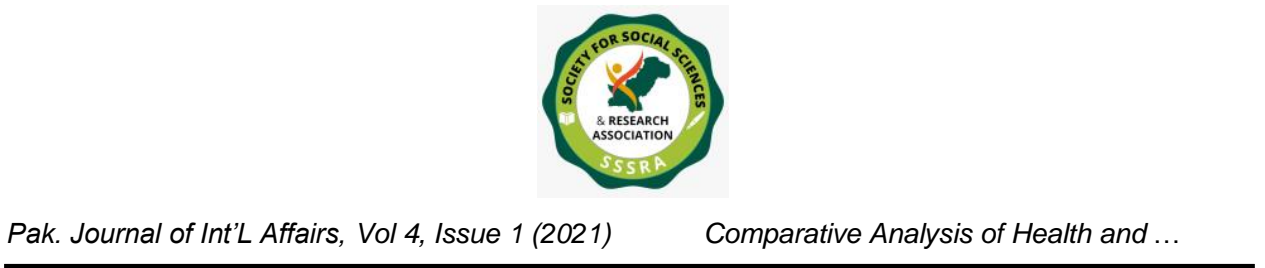

Significance level $=5 \%$

Looking at the probability value of Pesaran CD test, null hypothesis is accepted as the probability value is greater than 5 percent. This means there do not exist correlation among the cross-sectional residuals. In other words, residuals of the cross-sections are not dependent on each other.

\section{Conclusion and Recommendations}

Economic growth is a symbol of prosperity for an economy. There are number of factors that play role in stimulating economic growth. One such factor that helps increase the economic growth is the individuals health. Improved health of the labor can translate into increased output levels, higher level of productivity and efficient utilization of resources. Pooled OLS regression over the period from 1980-2017 is applied on panel data to find the results of health and economic growth nexus for three lower middle income countries that are Bangladesh, India and Pakistan.

Results showed that crude birth rate negatively impact the economic growth as the increasing number of population might be the unproductive labor force, becoming a liability rather than an asset for the economy. It also showed the relationship between life expectancy and growth to be significantly positive. This result is in line with the previous literature that is increase in life expectancy of population means improved health conditions of the individuals. Individuals with better health can produce higher output levels and utilize the resources efficiently. This leads to more production and in turn increased GDP of an economy.

Comparing the health impact on economic growth, statistics showed that coefficient of India is higher than Pakistan and Bangladesh. In case of Bangladesh, the relationship between health and GDP is positive and significant. That is one percent increase in health indicators causes $1.73 \%$ increase in the country's GDP. As for India one percent increase in health indicators causes $1.86 \%$ increase in the economic growth. While in Pakistan one percent increase in health indicators causes $1.56 \%$ increase in its GDP.

This means better health facilities in India is contributing more towards economic growth and development. Therefore, Pakistan and Bangladesh should focus on provision of better health facilities and improving their health indicators for attainment of increasing economic growth. 


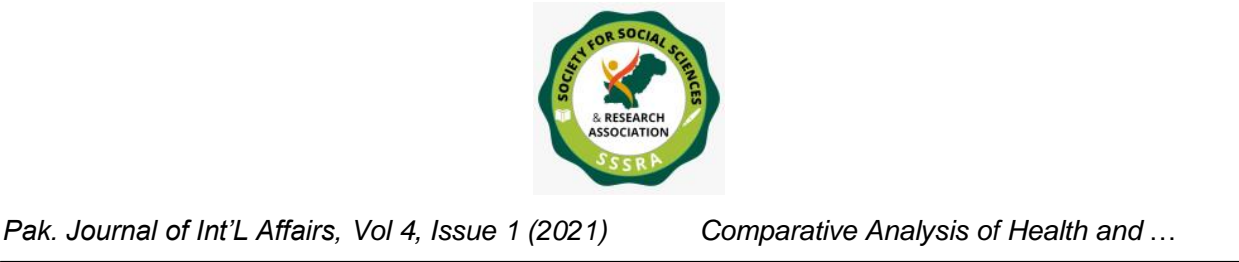

\section{References}

Akram, N., Ihtsham ul Haq Padda, \& Khan, M. (2008). The long term impact of health on economic growth in Pakistan. The Pakistan development review, 487-500.

Amiri, A., \& Ventelou, B. (2012). Granger causality between total expenditure on health and GDP in OECD: Evidence from the Toda-Yamamoto approach. Economics Letters, 116(3), 541-544.

Arora, S. (2001). Health, human productivity, and long-term Economic Growth. The Journal of Economic History, 61(3), 699-749.

Barro, R. (1996). Health and economic growth. World Health Organization.

Bloom, D. E., Canning, D., \& Sevilla, J. (2004). The Effect of Health on Economic Growth: A Production Function Approach. World Development, 32(1), 1-13.

Boachie, M. K. (2015). Effect of health on economic growth in Ghana:An application of ARDL bounds test to cointegration. Munich Personal RePEc Archive, 1-24.

Bokhari, H Z; Gardezi, A. (2013). Impact of Education And Health on Economic Development In Pakistan: A Case Study of Multan City. International Journal of Scientific And Engineering Research, 4(9), 653-659.

Carrion-i-Silvestre, J. L. (2005). Health care expenditure and GDP: are they broken stationary?. Journal of Health Economics, 24(5), 839-854.

Chaabouni, S., Zghidi, N., \& Mbarek, M. B. (2016). On the causal dynamics between CO2 emissions, health expenditures and economic growth. Sustainable cities and society, 22, 184-191.

Conceição, P. (2019). Human Development Report 2019: beyond income, beyond averages, beyond today: inequalities in human development in the 21st century. United Nations Development Programme. 


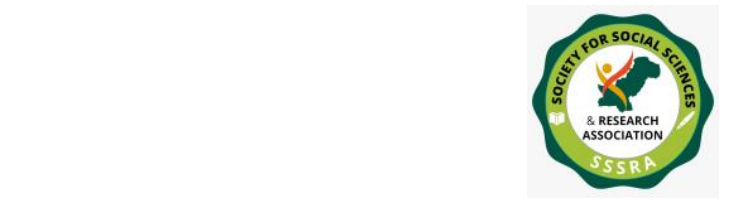

Pak. Journal of Int'L Affairs, Vol 4, Issue 1 (2021)

Comparative Analysis of Health and ...

Fogel, R. (1994). Economic Growth, Population Health And Physiology: The Bearing of Longterm Processes on the Making of Economic Policy. Cambridge: National Bureau of Economic Research.

Gong, L., Li, H., \& Wang, D. (2012). Health investment, physical capital accumulation, and economic growth. China Economic Review, 23(4), 1104-1119.

Goode, A., \& Mavromaras, K. (2014). Family Income and Child Health in China. China Economic Review, 29, 152-165.

Hakim, A. R., \& Subanti, S. (2019, October). The Growth determinant based on economic and non economic factors (empirical evidence in Central Java Province, Indonesia).

In Journal of Physics: Conference Series (Vol. 1341, No. 9, p. 092005). IOP Publishing.

Jasimuddin, M., \& Chowdary, M. (2018). Human Capital Development and Economic Growth in Bangladesh. Journal of World Economic Research, 7(2), 52-63.

Jawahar, S. K. (2013). Health Scenario in India. ICU Management and Practice, 6(4), 32-47.

Katrakilidis, C. K. (2016). The Dynamic linkages between economic growth, environmental quality and health in Greece. Applied Economic Letters,23(4), 217-221.

Kesikoğlu, F., \& Öztürk, Z. (2013). Relationship between human capital and economic growth: Panel causality analysis for selected OECD countries. Journal of Economic and Social Studies, 3(1), 153-162.

Kumar, S. B. (2017). Comparison and Analysis of Health Care Delivery System: Pakistan versus Bangladesh. Journal of Hospital and Medical Management, 3(1), 1-6.

Lago-Penas, S. C.-P.-F. (2013). On the relationship between GDP and health care expenditure: a new look. Economic Modelling, 32 124-129.

Linden, M., \& Ray, D. (2017). Aggregation bias-correcting approach to the health-income relationship: Life expectancy and GDP per capita in 148 countries, 1970-2010. Economic Modelling, 61, 126-136.

Mahumud, R. A., Rawal, L. B., Hossain, G., Hossain, R., \& Islam, N. (2013). Impact of Life Expectancy on Economics Growth and Health Care Expenditures: A Case of Bangladesh. Universal Journal of Public Health, 1(4), 180-186.

Mayer, D. (2001). The long-term impact of health on economic growth in Latin America. World Development, 29(6), 1025-1033. 


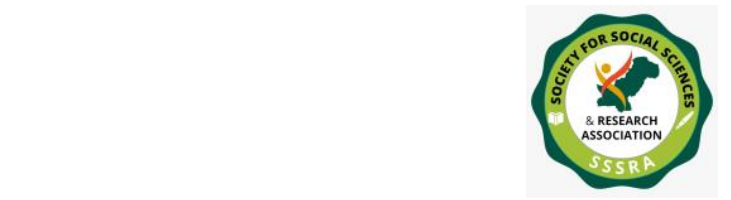

Pak. Journal of Int'L Affairs, Vol 4, Issue 1 (2021)

Comparative Analysis of Health and ...

Mladenović, I., Milovančević, M., Mladenović, S. S., Marjanović, V., \& Petković, B. (2016). Analyzing and management of health care expenditure and gross domestic product (GDP) growth rate by adaptive neuro-fuzzy technique. Computers in Human Behavior, 64, 524-530.

Narayan, S., Narayan, P. K., \& Mishra, S. (2010). Investigating the relationship between health and economic growth: Empirical evidence from a panel of 5 Asian countries. Journal of Asian Economics, 21(4), 404-411.

Ning, X., \& Zhang, J. (2018). Fiscal Decentralization and Local Public Health Expenditure: Empirical Analysis Based on Different Caliber Indicators and Provincial Panel Data. Chinese Health Economics, 37(6), 16-20.

Omri, A. (2013). CO2 emissions, energy consumption and economic growth nexus in MENA countries: Evidence from simultaneous equations models. Energy Economics, 40, 657664.

Piabuo, S. M., \& Tieguhong, J. C. (2017). Health expenditure and economic growth-a review of the literature and an analysis between the economic community for central African states (CEMAC) and selected African countries. Health Economics Review,7(1), 1-13.

Romer, P. M. (1990). Endogenous Techenological Change. Journal of political Economy, 98(5, Part 2), S71-S102.

Siddique, H. M. A., Mohey-ud-din, G., \& Kiani, A. (2018). Health, education and economic growth nexus: Evidence from Middle income Countries Growth Nexus. (December 7, 2018). Global Social Sciences Review, 3(4), 68-86.

Swift, R. (2011). The relationship between health and GDP in OECD countries in the very long run. Health Economics, 20(3), 306-322.

World Bank. (2014). World Development Indicators 2014. The World Bank.

Zaidi, S., \& Saidi, K. (2018). Environmental pollution, health expenditure and economic growth in the Sub-Saharan Africa countries: Panel ARDL approach. Sustainable cities and society, 41, 833-840. 